"The eye is the lamp of the body. If your eyes are healthy, your whole body will be full of

light." (Matthew, 6: 22)

\title{
Human iris polymorphisms: computer-based and genetic assessments of human irises and possible applications in human identification
}

\author{
KOZMA Zsolt², SÁNDOR Gábor ${ }^{3}$, PAMJAV, Horolma ${ }^{4}$, HUSZÁR András ${ }^{5}$
}

\begin{abstract}
During personal identification we can analyse the phenotypic or genotypic com-plexions of a human. The ancient histories of scientific activities in this field were related to the descriptive or measurable features, called phenotype analyses. In the last decades of the 20th century, during the era of human genetics, numerous polymorphic genetic markers were discovered investigating the human nuclear or mitochondrial DNA (deoxyribonucleic acid). The results of the Human Genome Project revolutionized the applications and opened an era of the investigations for externally visible characteristics (EVCs), the so called DNA based phenotyping (age, hair-, and eye-colour investigations) using informative molecular markers. The polymorphic characteristics of the human eye are well known. This partly originates from the vessel network and the layer order of the retina or the unique construction of the initial section of the optic nerve at the eye-ground. The iris' in- dividuality resides in its complex textural construction. The iris' colour and partly its patterns (variations of the Fuchs' crypts, nevi dots, Wolfflin nodules and con-traction furrows) are genetically determined. All of these previously mentioned iris polymorphisms led to the development of a number of automatic phenotypic or genotypic biometric personal identification practical applications.

The aim of this study is to briefly summarize the background of this topic condens-

ing those results which are available in this field, and to present our efforts related to a novel approach in the field of iris colour prediction.
\end{abstract}

\footnotetext{
http://bible.cc/matthew/6-22.htm /New International Version C1984/ (downloaded: 3007 2012)

Institute of Kaposvár, Network of Forensic Science Institutes (NFSI)

Institute of Kaposvár, Network of Forensic Science Institutes (NFSI)

Institute of Forensic Medicine, NFSI, Budapest

National University of Public Service, Faculty of Military Engineering

KOZMA et al: Human iris polymorphisms: computer-based and genetic assessments of human irises...
}

\section{Introduction}

The wonderful complexity of the human eye, originating from its visible or hidden structure, has affected the thinking of theologians, artists, scientific minds, scholars and believers in the metaphysical world, throughout the centuries. The classic idea that "...the eye is the mirror of the soul..." was already described in a translation of the New Testament. (Clement I. 19:3,

1768: 29) ${ }^{6,7}$ At the beginning of the nineteenth century, William Paley (1743-1805), a theolo- gian, in his fundamental work (Paley, 1802), called the eye an inexplicably complex "device" of human vision, which in itself is a proof of a "Creator"; in his view the proof of the existence of the creator God. Even in the world-famous work of Charles Darwin, which is known to be a scientific historical milestone, certain elements of self-criticism were found concerning the reliability of the theory of evolution, in which, because of the complexity of the human eye, he had doubts in its possible evolution by natural selection. (Darwin, 1859: 167)

In the 19th and 20th century, medical scientists described the anatomy of the eye and outlined the essence of its operation by performing functional tests.

The vessel network and the layer order of the retina (the light-sensitive membrane cov- ering the back wall of the eyeball that is continuous with the optic nerve) or the unique con- struction of the initial section of the optic nerve at the eye-ground (fundus) are the bases of unique retineal or fundus based automated person identification techniques which use optical coherence tomography. (Fercher et al., 1993: 113-114), (Naseri et al., 2012: 29-33) More- over, the 
uniqueness of the iris' single components (the iris is the coloured part of the eyeball that controls the amount of light that enters into the eye cavity), and its' textural variations opened opportunities onto development of independent biometric techniques (exp. IrisCode). (Flom, Safir, 1987), (Daugman, 1994)

After completion of the Human Genome Project $(\mathrm{HGP})^{8}$ scientists selected those candidate genes which may play a key role in the inheritance of human eye colour? These efforts made it possible to predict eye colour from any biological sample of a person. (Kayser et al., 2011) The aim of this study is to briefly summarize the background of this topic condensing those results which are available in this field, and present our efforts concerning a novel approach in the field of iris colour prediction.

\section{The structure of the human iris: colours and patterns}

The development of the human iris, partly from the neuroectodermal optic cup and partly from mesodermal elements, begins around the third month of gestation. After birth, the pig- mentation in the double cuboid cell layer (named iris pigment epithel: IPE) continues till the end of the first year. The iris (and the lens) play a role in dividing the human eye ball into two closed chambers: (1) anterior: between the cornea and iris and (2) posterior: between the lens and iris (Fig. 1.).

6 "Let us fix our thoughts upon him, and behold, with the eyes of our soul, his long-suffering purpose."

7 http://bible.cc/matthew/6-22.htm /New International Version (C1984/ (downloaded: 3007 2012)

8 HGP - an international scientific research project (1990-2003) with the leadership of the USA, with the primary goal of determining the order (sequence) of the purine and pyrimidine base pairs that make up the KOZMA et al: Human iris polymorphisms: computer-based and genetic assessments of human irises...

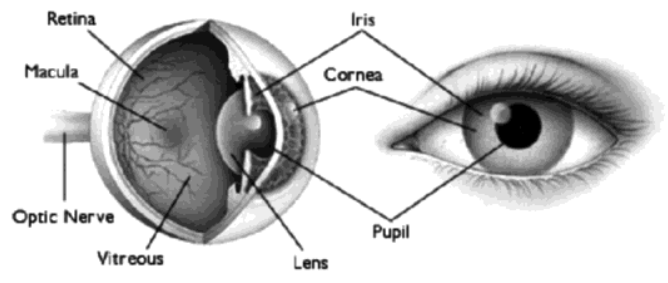

Figure 1. The main structure of the human eye $e^{9}$

The iris itself regulates the strength of illumination toward the retina. The high pigment content of the IPE and the pupil's own function, narrowing or dilating the pupil diameter using its dilator or sphincter muscles, block light from directly passing through the iris to the retina. The base structure of the iris is very complex. The frontal and saggittal sections of the human iris are highlighted in Figure 2. In case of the frontal section, the iris can be divided into two concentrical major regions, the pupillary zone (1): located between the pupillary frill (a black, anterior termination margin, the only visible part, of the posterior pigmented layer) and the collarette (the thickest area of the iris), the border toward the ciliary zone (2). The ciliary zone ends at the ciliary body. The wider inner part of this zone consists of a large number of radial and concentrical contraction furrows (overlapping the dilator and sphincter muscles) and Fuchs' $\operatorname{crypts}^{10}$, in the narrower outer, marginal part several peripherial crypts are located.
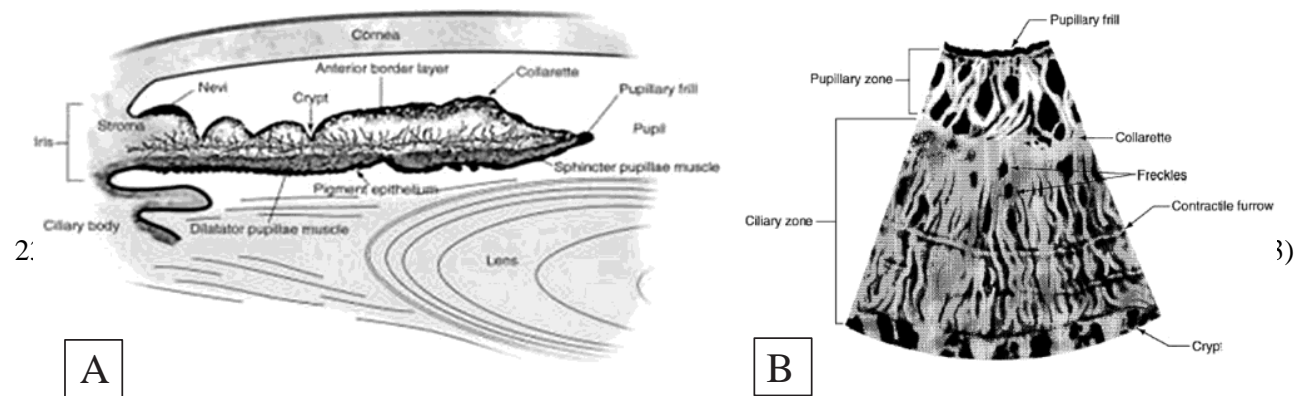

Figure 2. The structural base elements of a human iris. (A) sagittal section, (B) frontal section ${ }^{I I}$ 
9 The picture is available at http://web.princeton.edu/sites/ehs/laserguide/index.htm (downloaded: 1606 2012.)

10 Fuchs'crypts: Pit-like depressions or openings found near the collarette and near the periphery of the iris.

They allow the passage of aqueous humour from the anterior chamber into the stroma of the iris as the volume of the iris changes with dilatation and contraction. (Millodot, 2009)

11 http://math.ipm.ac.ir/scc/vision/iris/Iris-Recognition.htm\#db (downloaded: 1606 2012)

KOZMA et al: Human iris polymorphisms: computer-based and genetic assessments of human irises...

In humans, the different iris colours are determined partly by the concentration of mel- anin12 in the IPE13, and by the melanin content within the iris stroma, and finally by the stromal cellular density. The pigment content of the melanocytes is genetically determined. The final growth of iris colour is also influenced by the Rayleigh or Mie scattering 14 of light in the stroma. The visible anterior layer and some known natural patterns of iris are demon- strated in Figure 3.

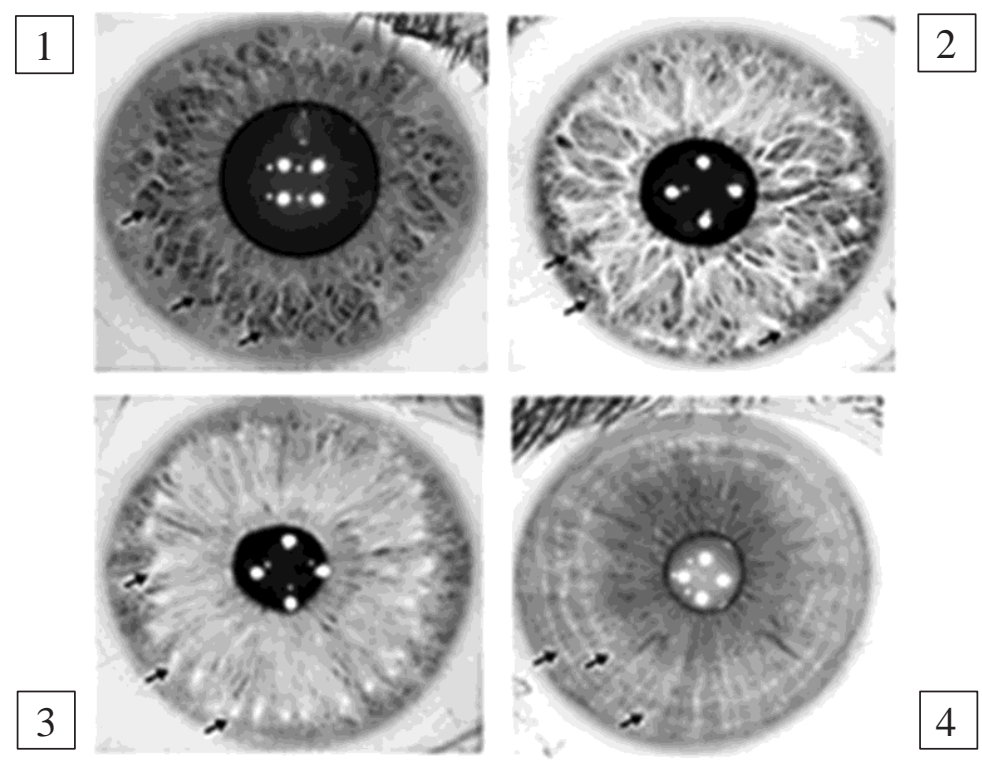

Figure 3. Changes in iris' frontal anterior texture (indicated by arrows):

1. Fuchs'crypts; 2. Nevi dots: collection of melanin pigment;

3. Wolfflin nodules: Patches of accumulated collagen fibrils;

4. Contraction furrows: overlapping the dilator and sphincter muscles ${ }^{15}$

\section{Role of the human iris in phenotypic biometric identification}

Recently, based on the uniqueness of the iris, a „science-like” and a truly scientific way to de- velop a mode of human identification has opened up. The former is called iridology ${ }^{16}$ which is rooted on the presumption that nearly all human inner organs have a designated topo- graphical location within the coloured human iris and any sort of change in a given position may indicate that an organ is healthy or diseased (Figure 4.). The world medical scientific community is divided about this kind of adaptation of iris polymorphisms, but it is a fact that

12 http://en.wikipedia.org/wiki/Melanin (downloaded: 1606 2012)

13 http://en.wikipedia.org/wiki/Iris_pigment_epithelium (downloaded: 1606 2012)

14 http://en.wikipedia.org/wiki/Rayleigh_scattering (downloaded: 1606 2012)

A5ARMESpicturesuerergriginally published as parts of the Figure 2. (Sturm, Larsson, 2009)

231

16 Iridology was re-discovered in the 1800's by Ignác Péczely (1826-1922), a Hungarian physician. He developed one of the first Iridology charts, published in his book (Péczely, 1873), it is the basis for most Iridology charts today.

KOZMA et al: Human iris polymorphisms: computer-based and genetic assessments of human irises...

old age, or a few human eye diseases especially several ophthalmological medical treatments cause changes in an iris' original colour. (Teus et al., 2002: 1085-1088), (Imesch et al., 1997:

117-123). Despite these exemptions medical science regards iridology as a pseudo-science, because the methods and results do not satisfy the criteria of so-called evidence based medi- cine. (Simon et al., 1979: 1385-1387), (Ernts, 2000: 120) 

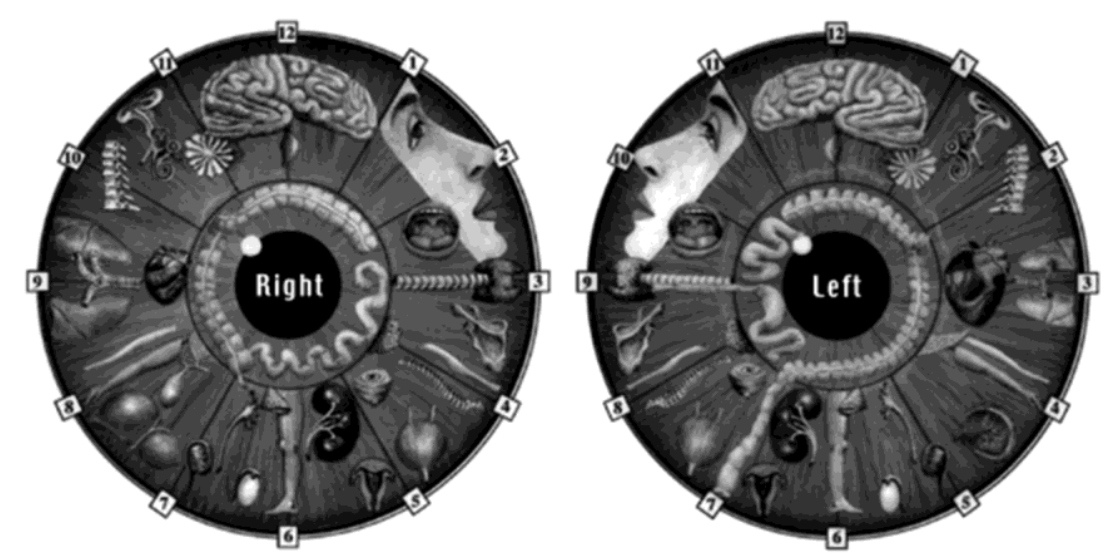

Figure 4. The projections of the organs on the human iris $^{17}$.

The other mode has been determined by the continuous scientific-industrial revolution of the 20-21st centuries, especially due to the developments of information technology (IT) and genetics. The research work in these fields has led to new technical adaptations rooted in the identification of the fingerprint-like polymorphisms of the iris texture, the fundus and the retina of the human eye. The best-known application of this effort is iris rapid photo- graphing and personal identification, that has become a significant part of up-to-date safe- ty and security technology systems (for computers, lap-tops, military facilities, border and airport access control systems, ATMs). The principle of such technology is the Daugman's ${ }^{18}$ conversion of the polymorphic surface texture of the iris into a biometric bar-code (Figure

5.), using the image processing technique based on the Gabor's ${ }^{19}$ wavelets, and the Gabor's transformation. (Daugman, 1994), (Gábor, 1946: 429-457) The first official application of this patented procedure was implemented in the United Arab Emirates. In this country, since

2001, during entry at the airport's, a continental or a harbour's border, a compulsory rapid IrisCode based control should be carried out on a person. (Daugman, 2004) Since then, many countries busiest airports [(Canada /all of the eight international airports(Aps)/, United King- dom /Heathrow Ap/, Germany /Frankfurt Ap/, Netherlands /Amsterdam Ap/, Japan /Narita Ap/)] have started to use the same technology, but Malaysia and Singapore are among those countries where the travellers crossings through the border are facilitated by this technology.

17 http://natural-people.com/wp-content/uploads/2011/04/iridology.jpg (downloaded: 2106 2012)

18 John Daughman is a physicist, Professor of Department of Computer Vision and Pattern Recognition, Cambridge University. Developer of the iris-based identification principle.

19 Dennis Gabor, born Gábor Dénes (Budapest, 05061900 - London, 0902 1979): Hungarian-born physicist. In 1971, for the development of the holography method he won the Nobel Prize in Physics.

KOZMA et al: Human iris polymorphisms: computer-based and genetic assessments of human irises...

AARMS (12) 2



Figure 5. The biometric bar-code of the human iris.

The identification is based on the extraction of the so called "Iris Code" using standardized conditions for photo shooting and Daugman's image processing. (The pixel stream in the upper left corner is a unique biometric identifier derived from the demodulation of $2-D$ [two dimensional] Gabor's wavelets, which is comparable to patterns stored in reference databases ${ }^{20}$ )

Commercial and military applications are also gaining ground: in laptops or cell phones instead of access codes 
(password), or in stadiums, buildings, airports and in closed military security zones to allow entries, iris-based recognition technologies and applications have been developed. (Daugman, 2009: 819-825)

Based on the examination of the iris of the human eyes, photograph and document recog- nition technologies and the developmental processes of the digital imagery techniques have led to a considerable number of discoveries which are patent protected nowadays. ${ }^{21}$

Today's facial recognition programs use the unique iris texture in part to recognize the individual facial components, cutting out digitally any parts if necessary, or even determining the different eye positions precisely, following the continuous traceability of the moving face images. (Liu et al., 2002: 693-698)

Finally, one of the most recent US patents involves the genetic prediction of human iris colour from unknown biological samples based on genetic analyses. (Kayser et al., 2011)

20 http://www.cl.cam.ac.uk/ jgd1000/csvt.pdf, (downloaded: 1107 2012)

21 In the USA, since 1976, among the available patent protections and patent claims handed in onto a

patent procedure, 46385 pieces are related to the human iris. http://www.patentstorm.us/search.html?q=iris\&s. $\mathrm{x}=0 \&$ s.y=0, browsed using the key word "iris" (downloaded: 1506 2012)

KOZMA et al: Human iris polymorphisms: computer-based and genetic assessments of human irises...

\section{The milestones in the colour assessments of human iris}

In the first decades of the 20Ith century, in possession of human genome mapping, the basic and applied biotechnological research have focused on the possible genetic inheritance of human physical traits and properties under the laws of genetics. These efforts have opened up new areas of genetic analysis based human identification, called DNA based phenotyping. In the first wave of such analyses, the investigations of those genetic characteristics which possibly take part in the inheritance of the human eye colour have also been involved. (Walsh et al., 2010) During these projects researchers intended to build up referential databases fol- lowed by the creation of predictive models which allow the reliable assignments of a human feature (eye colour, hair colour, skin colour etc.) related to results of analyses of candidate gene loci from biological samples of unknown origin. For such research and for any predic- tion, a standardized way of coding eye colours is essential.

Lots of historical antecedents of such coding procedures are well known. Initially, manual analyses and systematization of photographs was carried out. (Seddon et al., 1990: 1592-

1598) Such analyses were time-consuming; the results depended on the professionals' skills, knowledge, actual physical states, special abilities (exp. colour-discrimination sensitivity). Currently, such methods are not acceptable because of the required criteria of evidence- based-results, the repeatability and the (post) verifiability of the scientific statements. The results derived from such investigations are also unsuitable for the construction of computer databases. In 1998, the first automated iris colour-scale (RGB ${ }^{22}$ based) systematisation was published (German et al., 1998: 103110), then the automated iris shade recogniser system was announced in 2001 (Takamoto et. al., 2001: 412-419), with which the changes in nuance of the iris could be examined. The quantitative measurement protocol of the pigmentation of the human iris was developed in 2000, using the so-called CIELAB ${ }^{23}$ colour models. (Melgo- sa et al., 2000: 252-260) In 2003, the University of Wisconsin (US) reviewed the previously published scientific techniques in this field, and the application of an automated, so called equidistant colour space (CIE 1976 UCS or CIE $u^{\prime} v^{\prime}$ colour space) was suggested for iris identification in their technical report, which is essentially independent of the circumstances of the shooting. (Hunt, 1992), (Fan et al., 2003) Today, other constant colour scales namely the HSI, HLS and HSV ${ }^{24}$ colour models are frequently applied in digital imaging processes for real-time and continuous identification of moving objects. 234kuma et al., 2004: 28-39)

AARMS (12) 2 (2013)

22 RGB: This colour model is an additive colour model in which red, green, and blue light are added together in various ways to reproduce a broad array of colours. The name of the model comes from the initials of the three additive primary colours, red, green, and blue. (http://en.wikipedia.org/wiki/RGB)

23 CIE: The International Commission on Illumination (usually abbreviated CIE for its French name, Commission Internationale de l'éclairage) is the international authority on light, illumination, colour, and colour spaces. It was established in 1913 as a successor to the Commission Internationale de Photométrie

and is today based in Vienna, Austria. CIE L*a*b* (CIELAB) is the most complete colour space specified by the International Commission on Illumination. It describes all the colours visible to the human eye and was created to serve as a device independent model to be used as a reference. http://en.wikipedia.org/wiki/ International_Commission_on_Illumination (downloaded: 2207 2012)

24 HSI, HSV and HSL: These are cylindrical-coordinate representations of points in an RGB colour model.

The three representations rearrange the geometry of RGB in an attempt to be more intuitive and per ceptually relevant than the cartesian (cube) representation. Developed basically for computer graphics applications. http://en.wikipedia.org/wiki/HSL_and_HSV (downloaded: 


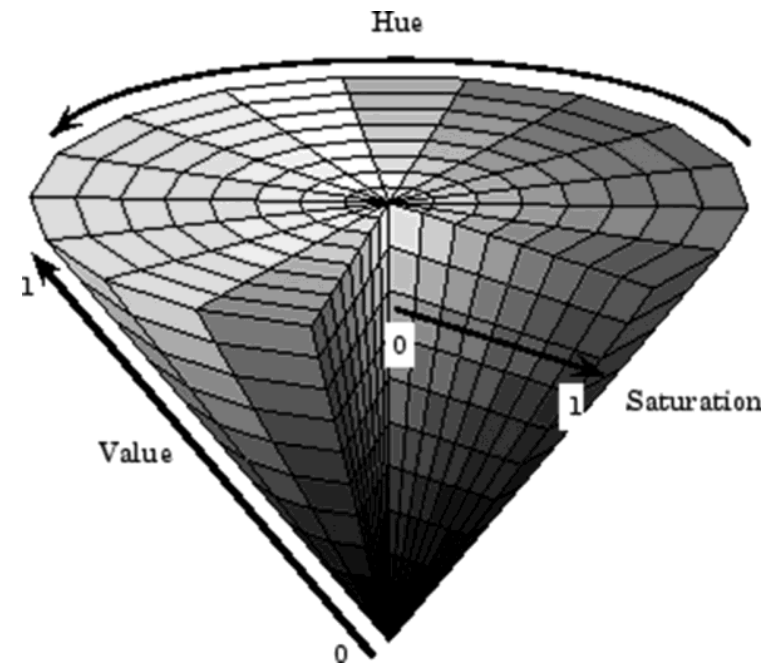

Figure 6. Illustration of the HSV colour space cone $e^{25}$

The HSI colour space based iris analysis, as the part of facial recognition software was published in 2002. (Liu et al., 2002: 693-698) We could not find data that the HSV colour model has been used to identify iris colour, so far.

One of our research aims was to point out that the Hue part value of the HSV colour space model is a useful and powerful tool for iris digital image processing in the work of preparing a prediction model for eye colour.

\section{Materials and methods}

The total workflow of our project, which was organized by the DNA Lab of the Institute of Forensic Medicine, NFSI, Budapest was summarized as follows (Figure 7.):

1. We collected informed written consent from 94 unrelated Hungarian individuals. We fixed the eye colours on the worksheets (both the donor and laboratory workers' opinion)

2. Buccal swab samples were collected using Whatman’s Sterile Omni Swab ${ }^{\circledR}$ (Catalog \#WB10-0004), according to the manufacturer's instructions.

25 http://www.mathworks.com/help/images/_f8-20792.html (downloaded: 1208 2012) The Hue values represent a $360^{\circ}$ colour wheel at the outer top circle of the HSV cylinder. The brown colour occupies the area from 0 to $40^{\circ}$, the green $60-180^{\circ}$ and the blue-gray $180-240^{\circ}$ of the colour circle.

KOZMA et al: Human iris polymorphisms: computer-based and genetic assessments of human irises... 


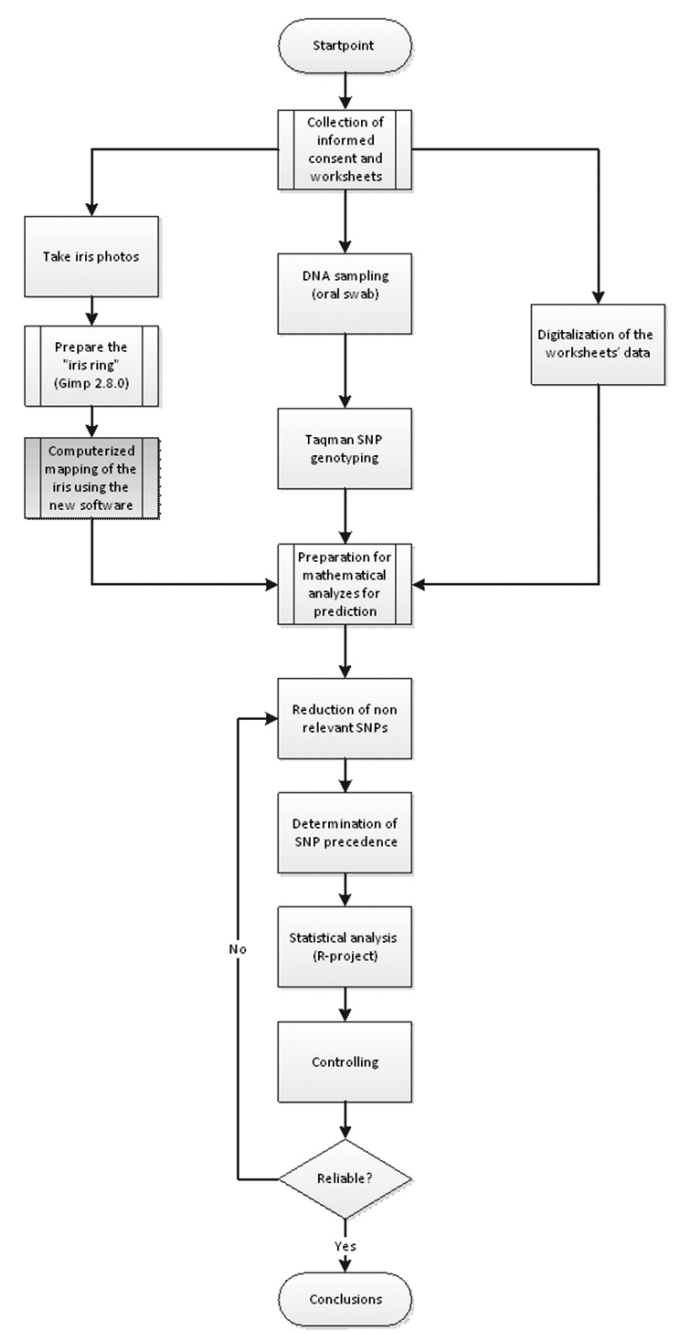

Figure 7. The workflow of the entire scientific project.

3. We performed a computerized mapping of the iris ring. Firstly, we took photos with a high resolution Nikon digital camera (Nikon D60 + Nikon SWM VR ED IF Macro

1:1), using standard adjustments followed by computer analyses. We took at least 2 pictures from each individual from both eyes.

4. To create the predicting model based on the Taqman ${ }^{\circledR}$ SNP $^{26}$, genotyping assay was carried out for those candidate gene loci which, in scientific literature, are known to play a role in the inheritance of the iris colour (Table 1.). Using the TaqMan ${ }^{\circledR}$ Assay

20 different SNPs' were tested for each human buccal swab sample according to the Applied Biosystems' protocol ${ }^{27}$. The six most informative loci were selected for the statistical analyses.

26 SNP: Single nucleotide polymorphism

27 http://tools.invitrogen.com/content/sfs/manuals/cms_057275.pdf (downloaded: 1008 2012)

28 National Center for Biotechnology Information http://www.ncbi.nlm.nih.gov (downloaded: 1108 2012)

KOZMA et al: Human iris polymorphisms: computer-based and genetic assessments of human irises...

\begin{tabular}{|c|c|c|c|c|c|}
\hline \multirow{2}{*}{\multicolumn{2}{|c|}{\begin{tabular}{l|c} 
SNPloci & Gene \\
AARMS & (12) 2 (20)
\end{tabular}}} & \multirow{3}{*}{$\begin{array}{l}\text { Cytogenetic } \\
\text { Band } \\
15 q 13.1 \mathrm{a}\end{array}$} & \multirow[b]{3}{*}{113} & \multicolumn{2}{|c|}{ Based on European } \\
\hline & & & & \multirow{2}{*}{$\begin{array}{l}\text { Genotype } \\
\text { frequencies } \\
\text { frequencie } \\
0,07510\end{array}$} & \multirow{2}{*}{$\begin{array}{l}\begin{array}{l}\text { Allele } \\
\text { frequencie\&3 }\end{array} \\
0,02642\end{array}$} \\
\hline rs12913832 & HERC2 & & & & \\
\hline rs16891982 & SLC45A2 & $5 \mathrm{p} 13.2 \mathrm{~d}$ & 58 & 0,11225 & 0,02793 \\
\hline rs1800407 & OCA2 & $15 q 13.1 \mathrm{a}$ & 112 & 0,39192 & 0,23762 \\
\hline rs12896399 & - & $14 \mathrm{q} 32.12 \mathrm{a}$ & 113 & 0,00008 & 0,00003 \\
\hline rs1393350 & TYR & $11 q 14.3 a$ & 113 & 0,45856 & 0,80025 \\
\hline rs 12203592 & IRF4 & $6 \mathrm{p} 25.3 \mathrm{~b}$ & 113 & 0,02288 & 0,01297 \\
\hline
\end{tabular}

Table 1. For building up the prediction model 6 SNPs were tested separately for each individual.

5. For statistical analyses and model building the MATLAB ${ }^{\circledR}$ and R-Project ${ }^{29}$ programs and formulas were used. We 
used a multinomial logistic regression model for the pre- diction analysis, as reported in a previous study of hair colour. (Branicki et al., 2011:

443-454) Consider eye colour, $y$, to be four categories blue, green, brown and inho- mogeneous, which are determined by the genotype, $x$, of $k$ SNPs, where $x$ represents the number of minor alleles per $k$ SNP. Let $\pi 1, \pi 2$, $\pi 3$, and $\pi 4$ denote the probability of blue, brown, green, and inhomogeneous, respectively. The multinomial logistic re- gression can be written as



where $\alpha$ and $\beta$ can be derived in the training set. Eye colour of each individual in the testing set can be probabilistically predicted based on his or her genotypes and the derived $\alpha$ and $\beta$,

$$
\begin{aligned}
& \pi_{1}=\frac{\exp \left(\alpha_{1}+\sum \beta\left(\pi_{1}\right)_{k} x_{k}\right)}{1+\exp \left(\alpha_{1}+\sum \beta\left(\pi_{1}\right)_{k} x_{k}\right)+\exp \left(\alpha_{2}+\sum \beta\left(\pi_{2}\right)_{k} x_{k}\right)+\exp \left(\alpha_{3}+\sum \beta\left(\pi_{3}\right)_{k} x_{k}\right)} \\
& \pi_{2}=\frac{\exp \left(\alpha_{2}+\sum \beta\left(\pi_{2}\right)_{k} x_{k}\right)}{1+\exp \left(\alpha_{1}+\sum \beta\left(\pi_{1}\right)_{k} x_{k}\right)+\exp \left(\alpha_{2}+\sum \beta\left(\pi_{2}\right)_{k} x_{k}\right)+\exp \left(\alpha_{3}+\sum \beta\left(\pi_{3}\right)_{k} x_{k}\right)} \\
& \pi_{3}=\frac{\exp \left(\alpha_{3}+\sum \beta\left(\pi_{3}\right)_{k} x_{k}\right)}{1+\exp \left(\alpha_{1}+\sum \beta\left(\pi_{1}\right)_{k} x_{k}\right)+\exp \left(\alpha_{2}+\sum \beta\left(\pi_{2}\right)_{k} x_{k}\right)+\exp \left(\alpha_{3}+\sum \beta\left(\pi_{3}\right)_{k} x_{k}\right)} \\
& \pi_{4}=1-\pi_{1}-\pi_{2}-\pi_{3} .
\end{aligned}
$$

Categorically, the colour category with the $\max (\pi 1, \pi 2, \pi 3, \pi 4)$ was considered a predict- ed colour.

29 MATLAB: (matrix laboratory) this is the major product of the MathWork (Apple Hill Drive, Natick, Massachusetts, USA). "It is a numerical computing environment and fourth-generation programming language... MATLAB allows matrix manipulations, plotting of functions and data, implementation of algorithms, creation of user interfaces, and interfacing with programs written in other languages, includeing C, C++, Java, and Fortran." (http://en.wikipedia.org/wiki/MATLAB) R-projekt APP: R is a language and environment for statistical computing and graphics. $\mathrm{R}$ provides a free, wide variety of statistical (linear and

nonlinear modelling, classical statistical tests, time-series analysis, classification, clustering, ...) and graphical techniques http://www.r-project.org (downloaded: 0708 2012)

KOZMA et al: Human iris polymorphisms: computer-based and genetic assessments of human irises...

6. We rechecked our predictive model with the samples which were included in the file building, and compared the software prediction (SP) ability to the participants' own opinions and to the Martin-Schultz scale (an eye colour scale, commonly used in phys- ical anthropology since the beginning of the 20th century).

In the present paper we demonstrate basically the computer based eye colour analysis in the above mentioned step 3.

\section{Results}

1. For the computerized mapping, we developed a new automated program for the iris colour analysis. Its flowchart is represented in Figure 8.

2. Using a standard computer graphic program (Gimp 2.8.0) we cut out the adequate parts of the iris rings' photos and stored the digitalized data without compression in PNG file format (Figure 9.).

3. Using the $\alpha$-channels in the PNG format we were able to create irregular contours from the iris rings storing an average 100000 pixels, respectively. The shadows of eyelids and eyelashes and/or other glittering areas or other artificial elements of the original pictures were cut out digitally.

4. The pixels were analysed individually using a newly developed software program to create a complex statistical dataset about the colour components of the iris based on the HSV colour model. In the printing industry, where the applications of high-preci- sion colour processing systems are required, those colour spaces are preferred which use the so called basic colour components (additive: RGB or the subtractive: CYMK colour models). In these complex colour scales millions of unique colour shades can ARASoduged (2) green or blue colours in the RGB, or the cyan, magenta, yellow and black colours in the CYMK model. In contrast, the HSV/HSL/HSI colour models have disadvantages compared to the RGB or CYMK, providing less information about the basic components of a distinct colour. In the case of an eye colour examination, however these kind of disadvantages provide benefits, because it is necessary to assign the colour results originating from the samples into only a few groups of the eye colour (greenish, bluish, brownish, or inhomogeneous), so there is no need to utilize the whole resolution ability of RGB or CYMK models (Table 2.). In other words it is not important to determine the compounds of the co- lours, but what colours are seen visually. 


\begin{tabular}{|c|c|c|c|c|c|c|c|c|c|c|c|c|c|}
\hline$R$ & $\mathrm{G}$ & B & Colour shades & $\mathrm{H}$ & $S$ & V & $\mathrm{R}$ & G & B & Colour shades & $\mathrm{H}$ & $\mathrm{S}$ & V \\
\hline 101 & 70 & 45 & & 27 & 55 & 40 & 23 & 131 & 231 & & 209 & 90 & 91 \\
\hline 101 & 58 & 23 & & 27 & 77 & 40 & 72 & 162 & 247 & & 209 & 71 & 97 \\
\hline 98 & 50 & 11 & & 27 & 89 & 38 & 112 & 167 & 219 & & 209 & 49 & 86 \\
\hline 142 & 73 & 18 & & 27 & 87 & 56 & 118 & 160 & 199 & & 209 & 40 & 78 \\
\hline 150 & 92 & 45 & & 27 & 70 & 59 & 110 & 159 & 206 & & 209 & 47 & 81 \\
\hline
\end{tabular}

Table 2. The table represents the very fine resolution ability of the RGB and the standard Hue $(H)$ values in the HSV colour space in case of several colour shades of the colour brown and blue, respectively. A given main colour can be created by the mixture of very different values of $R, G, B$ colour components. In contrast the $H$ value is standard in cases of different shades of a base colour.

5. In the first version of the analysis we determined those eye colour groups that are characteristic to the human eye, and that external observers are able to distinguish and determined the Hue value limits of those distinct colour groups, and the standard de- viations as well (Table 3.). It was clearly visible in the basic eye colours (brown, blue, green), but the grouping of some human irises are not so clear. Those coloured irises were named inhomogeneous. We realized that these complex colours are mixtures of the basic human eye colours mentioned before (greenish-blue, greenish-brown, etc.).

\begin{tabular}{|l|c|c|c|c|}
\hline Eye colour's code & 0 & 1 & 2 & 3 \\
\hline Eye colour & Blue-gray & green & brown & inhomogeneous \\
\hline Hue & $180-240$ & $60-180$ & $0-40$ & SD>55 \\
\hline Saturation & $<10$ & $>10$ & $>10$ & - \\
\hline $\begin{array}{l}\text { Pictures of iris ring } \\
\text { derived from our } \\
\text { own database }\end{array}$ & & & &
\end{tabular}

Table 3. The eyes' colour code system in our project with Hue representations. Four, very distinct iris colour groups could be represented. (See also the Notes 45, 47). All results of the eye colour, where finally the pixel analyses demonstrate at least 55 SD value, were defined as inhomogeneous.

KOZMA et al: Human iris polymorphisms: computer-based and genetic assessments of human irises... 


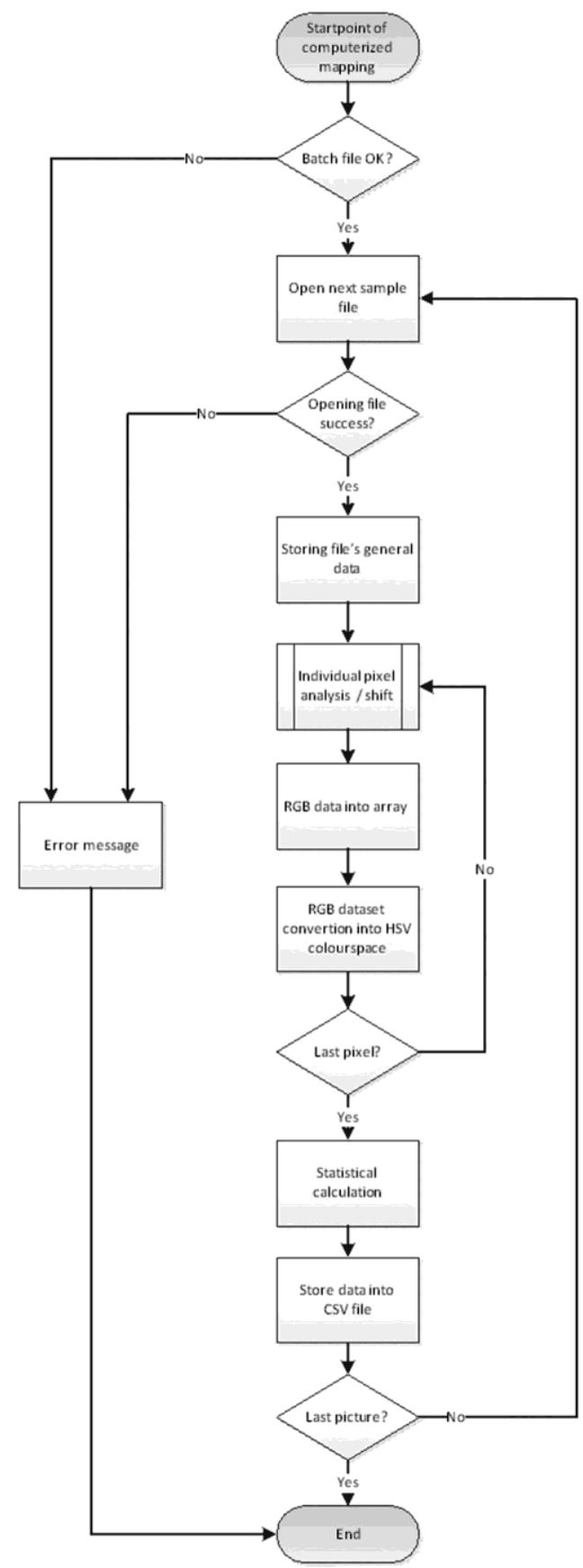

Figure 8. The flow chart of the computerized mapping of iris ring with the new software. KOZMA et al: Human iris polymorphisms: computer-based and genetic assessments of human irises...
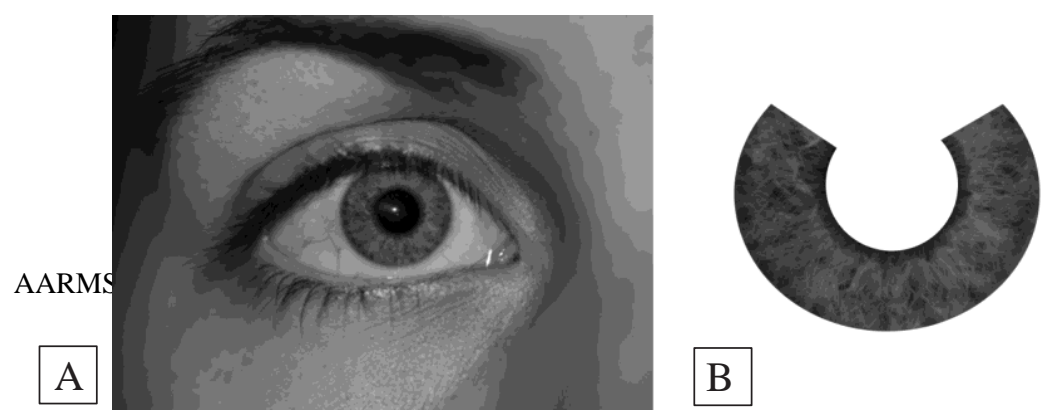

\section{B}

Figure 9. This figure represents an original iris picture (A), and the derived, digitalized colour iris ring cut out by Gimp 2.8 .0 (B) for the forthcoming computer analyses. (The shadows of eyelids and eyelashes and/or other glittering territories or other artificial elements of the original pictures were cut out digitally.)

\section{Discussion}


The fundamental assumptions of our project were the followings:

1. Photographing the iris of the human eye can be standardized, i.e. the taking of photos and processing of the statistical results are not dependent on changing external conditions.

2. The statistical definition of the brown, blue and green colours is possible using the stable Hue value colour wheel of the HSV colour cone. In the patent submission of the prediction model of the eye colour (Kayser et al., 2011), only two unique eye colour predictions - the blue one and the brown one - have been found, moreover the intermediate, and the non-identifiable subgroups' designations have been used by the authors, although in Europe the independent appearance of the green eye colour is relevant (independently the appearance is $3-5 \%$, while the green colour also plays considerable role as an additive colour component in the compound eye colours). In relation to the intermediate and the unidentifiable coloured irises, more precise statis- tical grouping models can be specified (we named this new group inhomogeneous).

3. A software program could be prepared for the automatic iris colour analysis, which could yield a suitable data set for any further statistical work on the way to build up a more accurate predictive model.

In the preparatory section of our research work, when the colour spaces were chosen, we took several photographs of the iris of a selected person. The captured pictures demonstrated considerable differences between the values of RGB of the investigated areas. This phenom- enon is the consequence of that fact that the typical human eye colours: brownish, greenish and bluish colours could be stirred in many ways from the three basic components of RGB, so that the colour shades represent only minimal differences.

In the same phase we also standardized the shooting conditions. We examined one iris of an individual using four different exterior illuminations; moreover using two different flashes we analysed the light relations and the effects of the flashes for the prepared pictures. Beside the exterior effects we compared the RGB and HSV colour space values. Our conclusions are summarized in the following points:

KOZMA et al: Human iris polymorphisms: computer-based and genetic assessments of human irises...

1. During the taking of photos of the iris of the same person, under the different external conditions (low light, scattered light, fluorescent or sunlight) the colour elements are very slightly affected. Using macro lens and flash (Nikon Speedlight SB800) in the close-ups $(30 \mathrm{~cm}>$ ) we could minimized the influence of external factors. There was no need to use an external flash.

2. Using application of the HSV colour scale the standard deviation could be decreased significantly deviation in each sample of the same individuals. Thus, for our goal, instead of the use of the three variable basic components of RGB colour space (with a higher standard deviation), the use of Hue value in the HSV colour space (with a smaller standard deviation) is more adequate.

3. The flash does not neutralize the reflections on the exterior surface of the eye. So it is necessary to pay attention during the making of the samples that the pictures are taken in a position, where the bright surfaces inducing the reflections (window, lighting bod- ies) cannot be seen. We observed that the following typical objects could also cover a part of the iris: a) outer reflective surfaces, b) eyelashes, c) eyelids, d) nose shade.)

We examined the freely available graphic programs as well, as to what kind of manner could present a statistical data set about the colour components of a given coloured picture. Finally we decided to manage our statistical work with the help of a self-developed program, because of the limited abilities of the other investigated programs. Before the implementation we targeted for the software the next basic propositions:

1. the ability to handle both the JPG and PNG formats,

2. in case of PNG files, the transparency of the preset PNG $\alpha$-channels could be handled by the software,

3. the ability of processing of bounded samples,

4. the ability to save the derived results in CSV or XLS formats,

5. The ability to store detailed information about the analysed samples as follows:

- The file name as an unique identifier,

- The number of processed pixels

- The minimum-, maximum-, average-, median and the standard deviation values of the components in the RGB colour scale. AARMS (12) 2 (2013)

- The minimum, maximum, average, median and standard deviation values of the components in the HSV colour scale.

The program applied the Java programming language ${ }^{30}$, using the Java ${ }^{\mathrm{TM}}$ SE Develop- ment Kit 7 from Oracle industry.

The database prepared by the software and the results of the investigated SNPs of a given person (we reported the genetic results elsewhere previously [(Völgyi et al., 2011)' (Kozma,

2011), (Kozma et al., 2012)] served as the basis of our mathematical model — using ordinal and multinomial logistic regression - for the eye colour prediction.

The algorithms based on these inputs (statistical and SNPs results) proved to be reliable when we rechecked the model using biological samples of the individuals included in the file building. Four iris colours (blue, green, brown and inhomogeneous) were predicted in 
30 Java is a programming language and computing platform first released by Sun Microsystems in 1995. It is the underlying technology that powers state-of-the-art programs including utilities, games, and business applications. Java runs on more than 850 million personal computers worldwide, and on billions of devices worldwide, including mobile and TV devices.

KOZMA et al: Human iris polymorphisms: computer-based and genetic assessments of human irises...

high statistical reliability. After retesting all of the 94 samples included in the model, the SP rate reached the $63 \%$ value. In a study, published previously, this ratio reached only $61 \%$ without the ability of discriminating the green colour. (Walsh et al., 2010) We also analysed the reliability of the program comparing the SPs to the participants' opinions about their own iris colours. We found that the SP rate reached the $90 \%$ value in this connection. We also compared our SPs to the results of the iris categorization according to the Martin-Schultz scale (an eye colour scale, commonly used in physical anthropology since the beginning of the 20th century). We found an $81 \%$ prediction accuracy in this connexion.

\section{Conclusions}

Based on the analyses performed, it can be stated that besides the Daughman's identification (IrisCode) of known persons, the prediction of human iris colour as an externally visible hu- man characteristic could be a useful application in those cases where the biological samples were collected from unknown individuals. This kind of human trait belongs to those three visible human characteristics (such as hair colour and human age) that can be reliably pre- dicted from DNA data sets. (Kayser et al., 2011), (Branicki et al., 2011 : 443-454), (Zubakov et al., 2010 : R970-R971)

This may open several civil and military applications in the future such as (a) missing per- son identifications; (b) analysis of biological samples from unknown individuals; (c) confirm and control eye witnesses; (d) disaster victim identification; (e) completion of data derived from other computer-assisted face-recognition programs and (f) forensic enquiries, or the work of military or civil intelligence.

One of the ultimate goals of our work is (in the IT input side) to achieve eye detection on images and documents. We are planning to perform the whole statistical analysis of a sample automatically, after the final preparation of images (iris rings).

At the output side, we wish to prepare the prediction model to an automatic iris drawing ability, too. For this aim we have to develop the method of deriving the statistical dataset because of the relatively frequent appearance of the inhomogeneous iris colour (34\% accord- ing to the software analysis). One kind of solution to this problem can be the separation of the basic colour components using the so called frequency distribution, and at the same time define the primary and secondary colour elements of such a compound iris colour.

In the future, using the same principles the investigations could be extended to the pre- diction of hair colour. With the development of science there is a high probability also, that other polygenically inherited human traits or predispositions can be predicted from biologi- cal samples.

These approaches clearly reflect the impulse of the DNA based phenotyping in the human identification process, which will open up a new area in the field of bioethical science as well. Without a wide scientific discussion, the interpretability of the results, and the acceptance of the method by broader society may be difficult.

KOZMA et al: Human iris polymorphisms: computer-based and genetic assessments of human irises...

\section{References}

BRANICKI, W., LIU, F., van DUIJN, K., DRAUS-BARINI, J. POŚPIECH, E., WALSH, S., KUPIEC, T., WOJAS-PELC, A., KAYSER M. (2011): Model-based prediction of human hair colour using DNA variants, Human Genetics, Vol. 129, Issue 4, pp. 443-454. http://www.ncbi.nlm.nih.gov/pubmed/21197618 (downloaded: 1008 2012) https://doi.org/10.1007/s00439-010-0939-8

CLEMENT I. Pope (1768): The First Epistle of Clemens Romanus to the Church of Corinth, Aberdeen: J. Chalmers, 19:3

DARWIN, Ch. (1859): The Origin of Species, London: In. J. M. Dent \& Sons Ltd. (ed.), p. 167, 1971

AARRASUGHA 2 (20135994): Biometric Personal Identification System Based on Iris Analysis, US 243 patent 5,291,560, Washington, D.C.: Patent and Trademark Office

DAUGMAN, J. (2009): Iris Recognition at Airports and Border-Crossings, In. Encyclopedia of Biometrics, Li, S. Z., Jain, A. K., (ed.), Springer US, pp. 819-825. http://link.springer.com/ referenceworkentry/10.1007\%2F978-0-387-73003-5_24 (downloaded: 1806 2012) https://doi.org/10.1007/978-0-387-73003-5_24

DAUGMAN, J., MALHAS, I (2004): Iris Recognition Border Crossing System in the UAE, International Airport Review Issue 2, http://www.cl.cam.ac.uk/ jgd1000/UAEdeployment.pdf (downloaded: 2407 2012)

ERNTS, E. (2000): Iridology: not useful and potentially harmful, Arch. Ophthalmol. Vol. 118 Issue. 1, pp. 120-1. https://doi.org/10.1001/archopht.118.1.120

FAN, S., DYER, C., HUBBARD, L. (2003): Quantification and Correction of Iris Colour, Technical Report 1495, Wisconsin: University of Wisconsin-Madison http://pages.cs.wisc. edu/ shaohua/research/iris/IrisColor_files/IrisTr1495.pdf (downloaded: 0708 2012)

FERCHER, A. F., HITZENBERGER, C. K., DREXLER, W., KAMP, G., SATTMANN, H. (1993): In Vivo Optical Coherence Tomography, American Journal of Ophthalmology Vol.

116 Issue 1, pp. 113-114. https://doi.org/10.1016/S0002-9394(14)71762-3 
FLOM, L., SAFIR A. (1987): Iris Recognition System, US patent 4,641,349, Washington, D.C.: Patent and Trademark Office,

GÁBOR D. (1946): Theory of Communication, Journal Institute of Electrical Engineers, Vol. 93, pp. 429-457.

GERMAN, E. J. et al. (1998): A novel system for the objective classification of iris colour and its correlation with response to $1 \%$ tropicamide, Ophthalmic and Physiological Optics Volume

18 , pp. $103-110$.

HUNT, R. W. G. (1992): Measuring Colour, 3rd Edition, Kingston-upon-Thames, Fountain Press, 1998.

IMESCH, P. D., WALLOW, I. H. L., ALBERT, D. M. (1997): The colour of the human eye: A review of morphologic correlates

and of some conditions that affect iridial pigmentation, Survey of Ophthalmology, Vol. 41, Supplement 2, pp. 117-123.

http://www.surveyophthalmol. com/article/S0039-6257\%2897\%2980018-5/abstract (downloaded: 1406 2012) KAYSER, M.

H., LIU, F., HOFMAN, A. (2011): Method for prediction of human iris colour, US Patent Application

20110312534 http://www.patentstorm.us/applications/20110312534/ fulltext.html (downloaded: 1406 2012)

KOZMA Zs. (2011): Katonai biogenetika, IV. Hadtudományi Doktorandusz Fórum 1027 2011, Budapest: Zrínyi Miklós Nemzetvédelmi Egyetem (oral presentation in Hungarian language)

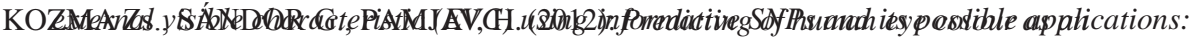
preliminary results, 5th International Symposium of the Osteuropaverein on Legal Medicine, 12 04-14 04 2012, Szeged, (oral presentation in English language)

LIU, H., WU, Y., ZHA, H. (2002): Eye states detection from colour facial image sequence, In: SPIE International Conference on Image and Graphics, Vol. 4875. pp. 693-698. http://www. cis.pku.edu.cn/vision/Visual\&Robot/publication/doc/liu-wuzha-eye_states_detection.pdf https://doi.org/10.1117/12.477054

KOZMA et al: Human iris polymorphisms: computer-based and genetic assessments of human irises...

MELGOSA, M., RIVAS, M. J., GOMEZ, L., HITA, E. (2000): Towards a Colourimetric Characterization of the Human Iris, Ophthalmic and Physiological Optics Vol. 20 Issue 3, pp. 252-260.

MILLODOT, M. (2009): Dictionary of Optometry and Visual Science, 7th edition, Butterworth- Heinemann

NASERI, A., POUYAN, A., KAVIAN, N. (2012): Automatic Detection of Retina Layers using Texture Analysis, International Journal of Computer Applications Vol. 46 Issue 1, pp. 29-33, OKUMA,

K., TALEGHANI, A., de FREITAS, J. F. G., LITTLE, J. J., LOWE, D. G: (2004):

A Boosted Particle Filter: Multitarget Detection and Tracking, In. European Conference on

Computer Vision, Vol. I, pp. 28-39. https://doi.org/10.1007/978-3-540-24670-1_3

PALEY, W. (1802): Natural Theology, and Tracts, The Works of William Paley, Vol. III., London: T. \& J. Almann, http://books.google.hu/books?id=Q-i7eOl42vAC\&pg=PA18\&lpg= PA18\&dq=William+Paley+human+eye \&source=bl\&ots=GyWP_0jG\&sig= M2wzYDMhw868TCzVRhISCXCdlXM\&hl=hu\&sa=X\&ei= defVT76qHcjR4QTBlfitAw\&ved=0CIQBEOgBMAQ4Cg\#v=onepage\&q\&f=false (downloaded: 3007 2012)

PÉCZELY I. (1873): A szivárvány-hártyáról, Budapest: Iris, Hunyadi Mátyás Intézet

SEDDON, J. M. et al. (1990): Evaluation of an Iris Colour Classification System, Investigative Ophthalmology \& Visual Science Vol. 31. No. 8. pp. 1592-1598.

SIMON, A., WORTHEN, D. M., MITAS, J. A. (1979): An evaluation of iridology, Journal of the American

MedAsabciation 242. pp. 1385-1387. http://books.google.hu/books?id=vp0J aSN88XAC\&printsec=frontcover\&dq=inauthor:\%22Clement+I+\%28Pope. $\% 29 \% 22 \& \mathrm{hl}=\mathrm{h}$ u\&sa=X\&ei=B8fZTicEuSD4gTjwfyVAw\&ved=0CEcQ6AEwAw\#v=onepage\&q\&f=false (downloaded: 2806 2012)

STURM, R.A., LARSSON, M. (2009): Genetics of human iris colour and patterns, Pigment Cell Melanoma Res. Vol. 22, pp. 544-562. https://doi.org/10.1111/j.1755-148X.2009.00606.x

TAKAMOTO, T., SCHWARTZ, B., CANTOR, L. B., HOOP, J. S., STEFFENS, T. (2001): Measurement of iris colour using computerized image analysis, Current Eye Research, Vol. 22

Issue 6. pp. 412-419. https://doi.org/10.1076/ceyr.22.6.412.5490

TEUS, M. A., MÁRQUEZ, E. A., SUESCUN, P. L. (2002): Incidence of iris colour change in latanoprost treated eyes, British Journal Ophthalmol, Vol. 86, Issue 10, pp. 1085-1088. http://bjo.bmj.com/content/86/10/1085.full?sid=0ec94f07-e666-4bb6-b86b-6b75e3290e8a (downloaded: 21 06 2012) https://doi.org/10.1136/bjo.86.10.1085

VÖLGYI A., ZALÁNA., SÁNDOR G., KIS Z., TOLDY E., SUSA E., PAMZSAV, H. (2011):

(downoaded: 14 of iris, hair and skin colour in the Hungarian population. Poster presentation at

AARMS (12)24thyorld Congress of the International Society for Forensic Genetics, Wien, Austria 08. 29.-09.03. 2011, http://isfg2011.book-of-abstracts.com/fileadmin/isfg2011/ISFG_BoA_2011_ Web.pdf (downloaded: 1408 2012)

WALSH, S., LIU, F., BALLANTYNE, K. N., van OVEN, M., LAO, O., KAYSE, M. (2010): IrisPlex: A sensitive DNA tool for accurate prediction of blue and brown eye colour in the absence of ancestry information, Forensic Science International: Genetics, Vol. 5 Issue 3, pp. 170-180. https://doi.org/10.1016/j.fsigen.2010.02.004

WALSH, S., LINDENBERGH, A., B., ZUNIGA, S., SIJEN, T., de KNIJFF, P., KAYSER, M., N., BALLANTYNE, K. (2010): Developmental validation of the IrisPlex system: Determination of blue and brown iris colour for

forensic intelligence, Forensic Sci. Int. Genet. 2010. https://doi.org/10.1016/j.fsigen.2010.09.008

ZUBAKOV, D., LIU F., van ZELM, M. C., VERMEULEN, J., OOSTRA, B. A., van DUIJN C. M., DRIESSEN G. J., van DONGEN J. J. M, KAYSER M., LANGERAK, A. W. (2010): Estimating human age from T cell DNA rearrangements, Current Biology Vol. 20, Issue 22, R970-R971 https://doi.org/10.1016/ j.cub.2010.10.022 
(Footnotes)

1 National Center for Biotechnology Information http://www.ncbi.nlm.nih.gov (downloaded: 1108 2012) 